\title{
Perforated shear + reinforcement bar connectors in a timber-concrete composite solution. Analytical and numerical approach
}

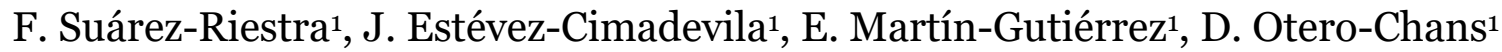 \\ (1) University of A Coruña, Department of Architectural, Civil and Aeronautical Building Structures, \\ Campus A Zapateira, 15071, A Coruña, Spain.
}

Corresponding author: felix.suarez@udc.es (Félix Suárez-Riestra)

ORCID:https://orcid.org/0000-0002-8839-5611 (Félix Suárez-Riestra)

https://orcid.org/0000-0002-8460-2097 (Javier Estévez-Cimadevila)

https://orcid.org/0000-0001-7464-4288 (Emilio Martín-Gutiérrez)

https://orcid.org/0000-0003-1738-252X (Dolores Otero-Chans)

\begin{abstract}
This paper presents a study of a novel shear connector in a timber-concrete composite solution, focussing on the determination of an analytical expression that makes it possible to predict its behaviour and a numerical analysis that describes it accurately. The shear connector is composed of a perforated steel plate inserted into a slot within the timber rib and glued, in combination with reinforcing corrugated steel bars affixed to the top of the plate. Previous tests made it possible to establish failure mode in different $\mathrm{T}$ composite section plate-rebar configurations. These results determine the effectiveness of the system in terms of force-slip behaviour, with systematic failure in the timber section. A simple predictive model is proposed to determine the ultimate capacity of the joint, taking into account the mechanical properties of timber in relation with the fracture plane and the timber-adhesive interface. This model makes it possible to apply a design process that is able to predict the stiffness of the connection. FEM models were analysed for each configuration in a variable load process equal to that used in the test, according to the standard procedure. A variable friction coefficient in contact definition made it possible to achieve an accurate descriptive model in association with the test procedure.
\end{abstract}

KEYWORDS: Wood; Adhesion; Analytical modelling; Mechanical testing. 


\section{Introduction and conceptual approach}

\subsection{Analytical studies of TCC systems}

The efficiency of a timber-concrete composite solution (TCC) is directly related to the effectiveness of the joint used to connect timber and concrete. The effectiveness of the resulting joint depends on its capacity to transmit the shear loads developed in the contact plane between materials, and it has to be stiff enough to limit the slip between the timber-concrete sections. In any case the behaviour of a timber concrete composite element depends on the properties of its components (timber and concrete) and connector characteristics. The partial composite action definitively results from the rigidity of the shear connections. Thus structural efficiency and an adequate design process depend on the ability to predict the stiffness of connections.

In behavioural terms the most effective connection is one that could satisfy the following conditions. Firstly, a connection between the timber section and concrete slab while undergoing stresses in an elastic range has to be stiff. Secondly, there has to be a ductile response when stresses develop in the plastic range.

In conventional $\mathrm{T}$ beams with an upper concrete flange connected to a timber beam it is not possible to use the transformed section method. The Navier-Bernoulli hypothesis is not appropriate in situations where the material interlayer is not fully rigid, resulting in a relative slip between the lower surface of the concrete and the upper surface of the timber. Most common shear connections exhibit a partial composite action with some relative slip at the interlayer, and this leads to analytical complexity that is increased in the case of timber and concrete by the heterogeneous nature of their physical and mechanical properties. The calculations of stresses and deformations in TCC are usually performed on the basis of linear-elastic behaviour for all the materials, in accordance with simplified design rules.

Some analytical methods have been developed to address the yielding of shear connectors. Some of them, like the Gamma Method proposed in Eurocode 5 [1] , assume the case of mechanically jointed timber beams based on the theory of linear elasticity with a flexible connection, and they do not contemplate plastic deformations of connectors when yielding. An overestimation of the post-yielding load-carrying capacity is therefore implicit in this method. Annex B of the Eurocode 5 proposes an analytical method for the case of mechanically jointed timber beams. The design method is based on the theory of linear elasticity with a flexible connection timber to timber. This proposal is derived from previous approximate solutions (Möhler [2] ) for flexible connections in timber, so the normative proposal is a simple approach to the real behaviour in a TCC composite beam where timber, concrete and connections are also characterised by time-dependent phenomena (Schänzlin and Fragiacomo [3]). This linear elastic method is based on the assumption that all materials remain within the linear elastic range until the first component fails. Moreover, consideration of the partial composite action resulting from the rigidity of shear connections means that this method is appropriate in some cases with very strong and stiff connectors. This method defines an effective bending stiffness $(E I)_{e f}$ to take into account the flexibility of the timber-concrete shear connection. Long-term analysis can be determined by an Effective Modulus Method (Ceccotti [4]), used to take into account the effect of creep of the different materials. In this method new coefficients $\left(\phi_{1}, \phi_{2}, \phi_{f}\right)$ modify the effective moduli of the materials $\left(E_{1, \text { eff }}, E_{2, \text { eff }}\right)$ and the slip modulus $\left(K_{\text {eff }}\right)$. 
Another proposal is the Elastoplastic Method, with solutions such as the Frozen Shear Forces Model that was introduced by Van der Linden [5]. This considers the plasticity of the connectors by assuming an elasto-plastic load-slip diagram. This proposal assumes simultaneous yielding in a group of shear connectors, and it also underestimates overall post-yielding stiffness. Frangi and Fontana [6] offer a solution that considers a failure load that is evaluated while assuming a rigid-perfectly plastic connection, with TCC failure occurring in the plasticization phase of the connector.

While the above-mentioned linear-elastic method is appropriate for solutions with strong and stiff connectors, the elastoplastic method is valid for low stiffness highly ductile connectors. In any case, the effectiveness of connections, in addition to the time-dependent properties of their materials, is a definitive parameter that makes it possible to predict the behaviour of solutions.

An intermediate solution was proposed by Zang and Grauvreau [7], describing an analytical method for predicting the load-deflection response of TCC with ductile shear connectors. This method combines the strengths considered in the Gamma Method with the behaviour assumed in the Frozen Shear Force Method, so shear connectors are assumed to be elasto-plastic, allowing them to yield progressively.

\subsection{Numerical studies in TCC systems}

Numerical modelling has been developed using the finite-element method (FEM) to determine the overall load-defection response of TCC systems, including non-lineal behaviour. Fragiacomo [8] considered a one-dimensional (1D) FE model composed of two parallel beams. The connectors were modelled with smeared spring elements. Liu [9] proposed a generic two-dimensional (2D) FE model which takes material nonlinearity and shear connector yielding into account. Most current studies consider three-dimensional (3D) FE models for short and cyclic load analysis (Van de Kuilen and Dejong [10]). Other researchers such as Dias et al [11] consider material with non-linear mechanical behaviour, using contact elements and friction to model the interaction between materials.

The application of any analytical methodology requires the prior determination of the behavioural characteristics of possible connection elements. It is therefore necessary to develop a particular analytical study for each connection type as a means of determining effective rigidity and the composite effect. Current $3 \mathrm{D}$ FEM models are able to predict the behaviour of these connections in terms of stiffness and failure mechanism, and they are a powerful analytical tool. However, it is still necessary to perform tests to calibrate models in terms of spring properties.

Many researchers such Penado and Dropek [12] or Tessler et al. [13] consider a finite element (FE) method in the analysis of bonded joints. Xiaocong He [14] shows the great advantages of this method, as it makes it possible to determine the mechanical properties of almost any geometrical shape under various load conditions. A finite element (FE) method makes it possible to analyse stress variations through thickness as well as plane stress distribution. Geometrical and material nonlinearities can be included, on condition that discretization, boundary conditions and loading are applied properly. This methodology was implemented as an appropriate way of predicting joint behaviour and stress distribution, and it achieves good accuracy in experimental and analytical studies (Gereke et al. [15], Vavrusova et al. [16] and Lavalette et al. [17]). Other recent investigations have worked on creep prediction models in addition to FEM analysis (Calí et al. [18]) an in the long-term response of composite system (Berardi et al. [19]), showing the versatility of the numerical models. 
F. Suárez-Riestra, J. Estévez-Cimadevila, E. Martín-Gutiérrez, D. Otero-Chans

\subsection{TCC systems. Basic typology and effectiveness}

There are many shear connection systems, and it is possible to categorize them into four groups: dowel-type, metal plate, shear key/anchor connections and glued-in plate connectors. This classification makes it possible to compare the effectiveness of each particular solution, and numerous studies have taken place on this question. Ceccotti [20] established a simple approximation of the behaviour of these different systems using a load-slip graph. This load-slip response of a connection under shear load in a comparison of different connector categories is used by Dias [21]. Lukaszewska et al [22] present the outcomes of an experimental programme comprising tests on seven series of different connector types, including glued connectors (steel mesh-SM). This classification of the mechanical behaviour of glued joints characterises them in terms of strength and stiffness, with linear behaviour up to failure which occurs at low deformation values.

Two different types of glued connections can be described. The most simple bond layer between vertical wooden beams and horizontal concrete flanges was investigated by Pincus [23]. The entire test showed no appreciable slip between the materials prior to final failure, indicating true composite action. Brunner et al. [24] tested a similar composition in a wet to wet solution, indicating that the use of a continuous adhesive layer can distribute the shear forces uniformly over the entire surface and thus avoid the common concentration of local forces in mechanical connections. Kanócz and Bajzecerová [25] describe real response and theoretical modelling of composite beams with the use of an adhesive to bond wet concrete and timber. A second alternative is the use of adhesive in combination with other elements. In this case the adhesive is used to ensure the connection between the shear connector and timber. The shear connector can be discrete with separate elements at a specific distance, or continuous along the element. In the first case Ceccotti el al. [26] reported the outcomes of a compressive test performed on a composite system made using corrugated rebar placed in epoxy resin-filled holes in a timber beam. Piazza and Ballerini [27] tested two glued-in connectors, one made with bent dowels and the other one composed of combined concrete thick dowels coupled with steel ribbed dowels epoxy-glued to timber. The continuous alternative with a different steel plate and mesh is described by Bathon and Graf [28] and Clouston et al. [29], showing high strengths and stiffness, even in solutions in which the steel plate is replaced by a glued-in perforated plywood mesh (Daňková et al. [30]).

\section{A novel glued-in TCC system. Analytical and numerical approach}

This paper analyses a novel glued-in discrete shear connector system that has been shown to be highly effective for the connection of a lower glued-laminated timber section and an upper flange of reduced thickness composed of fibre reinforced concrete. This composite system is made from a steel mesh connector glued into a lower timber section in combination with reinforcement steel bars embedded in the concrete upper slab. In the different configurations a high strength and stiffness was found in tests, and a very high failure load was reached with a minimum value of deformation, allowing the system to behave very similarly to fully composite action, with a majority shear failure mode in the adhesive-timber contact zone.

The focus of this research is to determine an analytical and numerical methodology that makes it possible to predict the behaviour of a connection system in relation to the overall dimensions of the connector and the specific area of the interface between 
the plate and the timber section. A simple formulation is proposed based on these factors, taking into account the fundamental mechanical property of the timber that determines joint failure, to determine the ultimate capacity of the joint and force-slip behaviour in the initial linear stage and in the subsequent plastic phase. This analytical formulation makes it possible to predict the effectiveness of the system in relation to a geometric configuration in the identified failure mode, thereby creating a simple and effective design tool.

The numerical analysis comprises 3D FEM models that have taken into account the different factors that intervene in the behaviour of the joint. In addition to the particular properties of each section, including all of their constituent materials, a particular study has been carried out of the contact interface definition. The use of an unconventional variable friction coefficient in the definition of the contact surface means that it is possible to reproduce load-slip behaviour in a load-time scenario similar to that used in standard tests. The fit of the model with test results would permit particular analytical procedures, such as stress distribution in each component of the joint or contact stress distribution in the plate-timber interface.

\subsection{Material and geometrical configuration}

The shear connector is composed of a perforated steel plate inserted into a slot within the timber rib and connected by adhesive. The S235JR [31] galvanized steel plate is 5 $\mathrm{mm}$ thick and $90 \mathrm{~mm}$ long, with $40 \mathrm{~mm}$ inserted in the timber slot and $50 \mathrm{~mm}$ inside the upper concrete slab. The perforation corresponds to staggered round holes (at $60^{\circ}$ ) with a $10 \mathrm{~mm}$ hole width and $15 \mathrm{~mm}$ hole spacing Rv 10-15 [32].

This plate is complemented with two combinations of reinforcing corrugated B500S steel bars [33] configurations. In the first configuration three $\varnothing 8 \mathrm{~mm}$. bars were placed in the upper perforations of the plate, in a transverse arrangement. The second configuration consists of two $\varnothing_{12} \mathrm{~mm}$. bars welded to the upper edges of the plate in a longitudinal arrangement. Three possible configurations are therefore considered (Fig. 1): perforated plate (T1), perforated plate reinforced with transverse bars (T2) and perforated plate with longitudinal bars (T3).

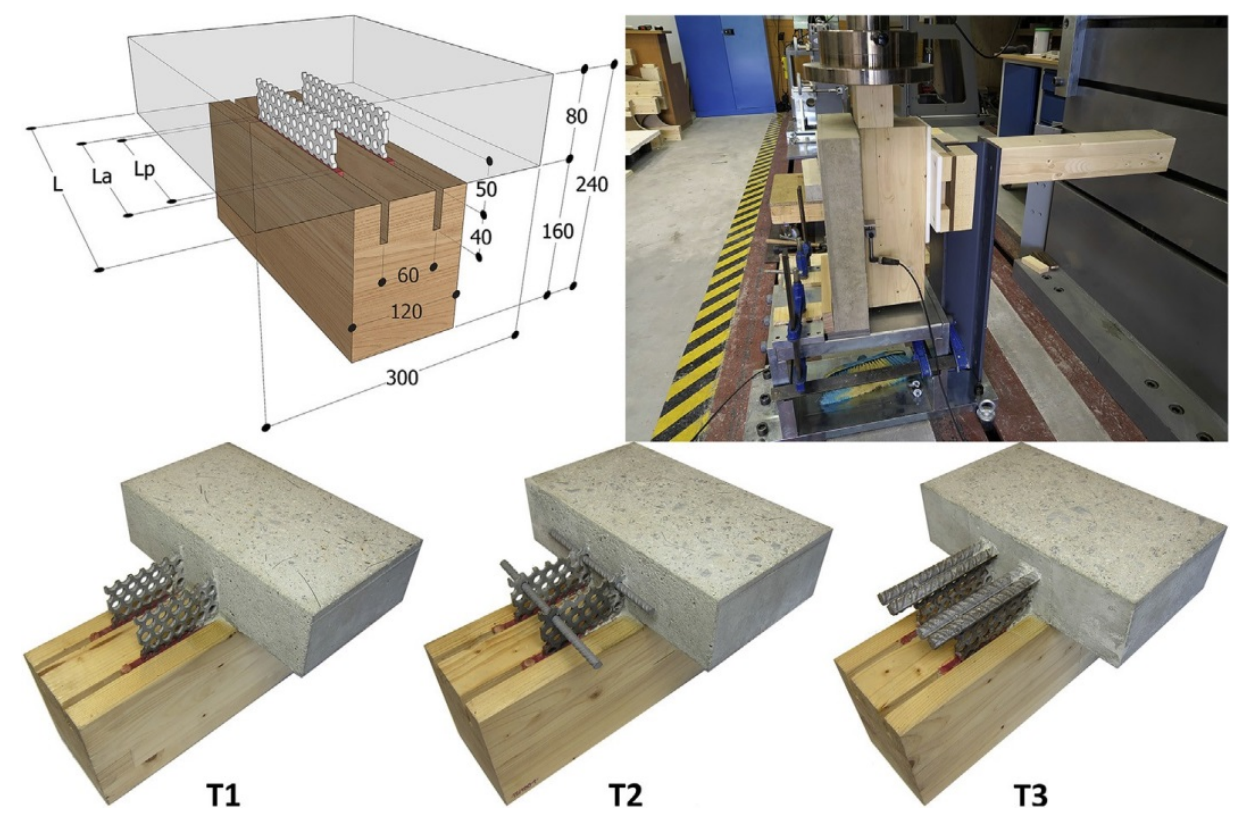

Fig. 1. Specimen configurations and dimensions. Test mechanism. 
A glued laminated timber rib with strength class GL28h [34] and $120 \times 160 \mathrm{~mm}$ cross section was considered. Two $8 \mathrm{~mm}$ wide and $42 \mathrm{~mm}$ deep continuous slots were made $60 \mathrm{~mm}$ apart along its upper face. This slot size makes it possible to use a 1.5 $\mathrm{mm}$. thick adhesive layer between the plate and the timber surface. Hilti Hit-RE 500 v3 two-component epoxy adhesive was used for the glued connection. The material properties of this fully cured adhesive are described by the manufacturer.

The upper slab consists of $300 \times 80 \mathrm{~mm}$ cross-section fibre-reinforced concrete. SikaFiber T-48 SL macro fibres made of polyolefin certified according to EN 148892:2008 [35] were added to the concrete to improve its flexural strength and cracking behaviour.

This configuration was used in two lengths, of $180 \mathrm{~mm}$ and $300 \mathrm{~mm}$. Six different combinations were therefore considered, taking into account the said lengths and the three possible configurations of the plate-rebar assembly. (Table 1).

Table 1: Configuration and basis characteristics of the specimens.

\begin{tabular}{|c|c|c|c|c|c|c|c|c|}
\hline Specimen & $\begin{array}{c}\text { Timber cross- } \\
\text { section }\end{array}$ & Concrete slab & $\mathrm{L}$ & LP & $\mathrm{La}$ & Connection elements & Contact area & $\begin{array}{l}\text { Number of } \\
\text { specimens }\end{array}$ \\
\hline $\mathrm{T} 1 / 180$ & $120 \times 160$ & $360 \times 80$ & 360 & 180 & 200 & $2 *$ PSP & $4 \times 200 \times 40$ & 3 \\
\hline $\mathrm{T} 1 / 300$ & $120 \times 160$ & $480 \times 80$ & 480 & 300 & 320 & $2 * \mathrm{PSP}$ & $4 \times 320 \times 40$ & 3 \\
\hline $\mathrm{T} 2 / 180$ & $120 \times 160$ & $360 \times 80$ & 360 & 180 & 200 & $2 * \mathrm{PSP}+2 * \varnothing 8 \mathrm{TR}$ & $4 \times 200 \times 40$ & 3 \\
\hline $\mathrm{T} 2 / 300$ & $120 \times 160$ & $480 \times 80$ & 480 & 300 & 320 & $2 * \mathrm{PSP}+3^{*} \varnothing 8 \mathrm{TR}$ & $4 \times 320 \times 40$ & 3 \\
\hline $\mathrm{T}_{3 / 180}$ & $120 \times 160$ & $360 \times 80$ & 360 & 180 & 200 & $2^{*} \mathrm{PSP}+4^{*} \varnothing 12 \mathrm{LR}$ & $4 \times 200 \times 40$ & 3 \\
\hline $\mathrm{T}_{3} / 300$ & $120 \times 160$ & $480 \times 80$ & 480 & 300 & 320 & $2^{*} \mathrm{PSP}+4^{*} \varnothing 12 \mathrm{LR}$ & $4 \times 320 \times 40$ & 3 \\
\hline
\end{tabular}

PSP: Perforated Steel Plates Rv 10-15 (DIN 24041:2002-12). Dimensions 90xLpx5 mm.

TR: Transversal Reinforcement rebar $\emptyset 8$ mm, B50oS (UNE EN 36068:2011). Length $180 \mathrm{~mm}$.

LR: Longitudinal Reinforcement rebar Ø12 mm, B50oS (UNE EN 36068:2011). Length 30+Lp+30 mm.

\section{Experimental Program}

The behaviour of a composite system in a design criterion should be based on tests and supported by a conceptual model that properly describes the stiffness properties of the shear connector. The stiffness properties of connectors are usually evaluated using a push-out shear test according to EN 26891:1992 [36].

Strength is quantified as the maximum load $\left(F_{\max }\right)$ applied when failure occurs, and stiffness is quantified by the slip modulus at different load levels. Two slip moduli are considered as a result of this test, $K_{i}$ corresponding to the initial slip modulus and $K_{s}$ or the slip modulus. Both of these are obtained from two-step results, where $v_{0,1}$ and $v_{0,4}$ are slips at the concrete-timber interface under a load of $10 \%$ and $40 \%$ of an initial ultimate estimated load $\left(F_{\text {est }}\right)$. Fig. 2 shows the most important test process parameters and determining values that can be obtained.

In accordance with the test standard, the estimated load $\left(F_{\text {est }}\right)$ can vary significantly in comparison with the actual maximum load value $\left(F_{\max }\right)$, and should be adjusted in subsequent tests. In some case the $F_{\text {est }}$ value was lower than $F_{\max }$ so that an adjustment was required to bring both values closer. The fact that the EN 26891:1992 standard [36] defines the slip modulus $\left(K_{s}\right)$ from an initially estimated load value $\left(F_{\text {est }}\right)$ instead of the maximum load value $\left(F_{\max }\right)$ leads to distortion in the evaluation of behaviour, particularly in the initial phase when the $F_{\text {est }}$ value is greater than the $F_{\max }$ value. 


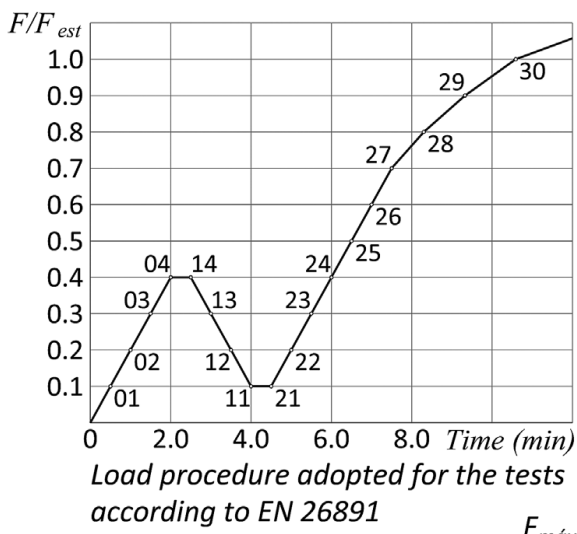
according to EN 26891

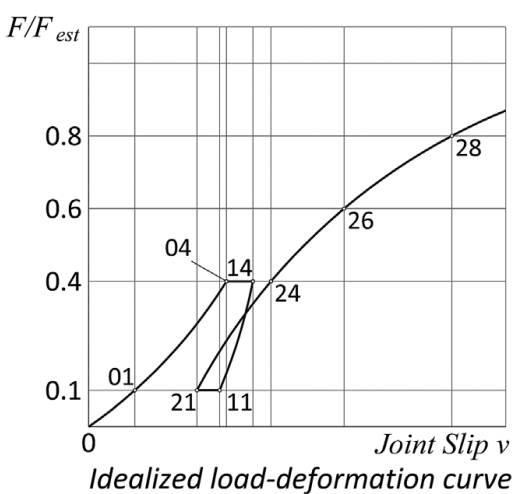

$F_{\text {máx }}$ Maximum Load

$F_{\text {máx }}$ Estimated Maximun Load

$v_{01}$ Displacement for the value $0.1 \cdot F_{\text {est }}$

$v_{04}$ Displacement for the value $0.4 \cdot F_{\text {est }}$

$v_{i, \text { mod }}=4 / 3 \cdot\left(v_{04}-v_{01}\right)$ Modified initial displacement

$\kappa_{i}=0.4 \cdot F_{\text {est }} / v_{i}=0.4 \cdot F_{\text {est }} / v_{04}$ Initial Slip moduli $K_{s}=0.4 \cdot F_{\text {est }} / v_{i, \bmod }$ Slip moduli

Fig. 2. Loading procedure adopted for tests and idealized load-slip curve.

Table 2 summarizes the results obtained in these tests, corresponding to a series of three specimens for each configuration, in accordance with the standard proposal. In the case of the T-180 configuration the greatest difference between values occurs for T1-180, where the $F_{\max }$ value obtained in test differed +17.8 to $-21.5 \%$ from the previous $F_{\text {est }}$. In the case of the T-300 configuration two particular situations caused distortion. Firstly, in T1-300-1 a difference of -20.2\% between $F_{\max }$ and $F_{\text {est }}$ was obtained in the test. Secondly, an extremely high $F_{\max }$ value was found in T3-300-2, $\mathbf{+ 2 0 . 9 \%}$ over the estimated value $\left(F_{\text {est }}\right)$.

Table 2: Test results according to UNE EN 26891:1992.

\begin{tabular}{|c|c|c|c|c|c|c|c|c|c|c|c|c|}
\hline \multirow[t]{3}{*}{ Type } & \multirow[t]{3}{*}{ Specimen } & \multirow{3}{*}{$\frac{\text { Force }}{\text { Fest }_{\text {est }}}$} & \multicolumn{7}{|c|}{ Slip Moduli } & \multirow{3}{*}{$\begin{array}{c}\text { Contact } \\
\text { area }\end{array}$} & \multirow{2}{*}{$\begin{array}{c}\begin{array}{c}\text { Shear } \\
\text { stress }\end{array} \\
\tau_{\mathrm{s}}\end{array}$} & \multirow{3}{*}{ Average } \\
\hline & & & $F_{\max }$ & Dif & Average & $\mathrm{K}_{\mathrm{s} \text {,Fest }}$ & Average & $\mathrm{K}_{\mathrm{s}, \mathrm{Fmax}}$ & Average & & & \\
\hline & & & {$[\mathrm{kN}]$} & $\%$ & {$[\mathrm{kN}]$} & {$[\mathrm{kN} / \mathrm{mm}]$} & & & & & [MPa] & \\
\hline \multirow[t]{3}{*}{$\mathrm{T} 1 / 18 \mathrm{O}$} & $\mathrm{T} 1 / 180-1$ & 150.0 & 182.6 & +17.8 & 170.2 & 707.5 & 786.8 & 709.9 & 785.3 & $4 \times 200$ & $5 \cdot 7$ & $5 \cdot 3$ \\
\hline & $\mathrm{T} 1 / 18 \mathrm{o}-2$ & 200.0 & 170.9 & -14.6 & & 794.1 & & 817.2 & & $\times 40$ & 5.3 & \\
\hline & $\mathrm{T} 1 / 18 \mathrm{o}-3$ & 200.0 & 157.1 & -21.5 & & 859.0 & & 828.9 & & & 4.9 & \\
\hline \multirow[t]{3}{*}{$\mathrm{T} 2 / 18$} & Т2/18o-1 & 200.0 & 173.8 & -13.1 & 181.6 & 1131.8 & $973 \cdot 3$ & 1189.5 & 995.5 & $4 \times 200$ & 5.4 & $5 \cdot 7$ \\
\hline & T2/180-2 & 200.0 & 180.6 & -9.7 & & 929.4 & & 944.2 & & $\times 40$ & 5.6 & \\
\hline & T2/180-3 & 200.0 & 190.3 & -4.9 & & 858.5 & & 852.8 & & & 5.9 & \\
\hline \multirow[t]{3}{*}{$\mathrm{T}_{3} / 18$} & $\mathrm{~T}_{3} / 180-1$ & 200.0 & 167.6 & -16.2 & 185.6 & 858.8 & 915.8 & 912.2 & 937.1 & $4 \times 200$ & 5.2 & 5.8 \\
\hline & $\mathrm{T}_{3} / 18 \mathrm{O}-2$ & 200.0 & 194.0 & -3.0 & & 1164.3 & & 1189.0 & & & 6.1 & \\
\hline & $\mathrm{T}_{3} / 18 \mathrm{o}-3$ & 200.0 & 195.1 & -2.5 & & 724.3 & & 710.0 & & & 6.1 & \\
\hline \multirow[t]{3}{*}{$\mathrm{T} 1 / 30$} & $\mathrm{~T} 1 / 300-1$ & 300.0 & 239.4 & -20.2 & 240.3 & 2616.7 & 2939.0 & 2622.2 & 3034.1 & $4 \times 320$ & $4 \cdot 7$ & $4 \cdot 7$ \\
\hline & $\mathrm{T} 1 / 300-2$ & 240.0 & 248.5 & +3.5 & & 2706.1 & & 2641.5 & & & 4.9 & \\
\hline & $\mathrm{T} 1 / 300-3$ & 240.0 & 232.9 & -2.9 & & 3494.0 & & 3838.5 & & & 4.5 & \\
\hline \multirow[t]{3}{*}{$\mathrm{T} 2 / 30$} & T2/300-1 & 240.0 & 262.6 & +9.4 & 264.7 & 2580.0 & 2556.6 & 2633.4 & 2638.0 & $4 \times 320$ & 5.1 & 5.2 \\
\hline & $\mathrm{T} 2 / 300-2$ & 240.0 & 270.0 & +12.5 & & 2788.0 & & 2874.6 & & & $5 \cdot 3$ & \\
\hline & T2/300-3 & 240.0 & 261.7 & +9.0 & & 2301.9 & & 2406.0 & & & 5.1 & \\
\hline \multirow[t]{3}{*}{$\mathrm{T}_{3} / 30$} & $\mathrm{~T}_{3} / 300-1$ & 270.0 & 252.5 & -6.5 & 276.0 & 4298.1 & 3368.4 & 5131.9 & 3782.5 & $4 \times 320$ & 4.9 & 5.4 \\
\hline & T3/300-2 & 270.0 & 326.4 & +20.9 & & 3061.0 & & 3237.4 & & & 6.4 & \\
\hline & $\mathrm{T}_{3} / 300-3$ & 270.0 & 249.2 & -7.7 & & 2746.1 & & 2978.2 & & & 4.9 & \\
\hline
\end{tabular}

Maximum loads (Fmax) and average shear stress ( $\tau$ s) in the contact area. 
These tests show majority failure in the plate-timber contact zone (Fig. 3), so it is possible to establish a relation between the ultimate load $\left(F_{\max }\right)$ and stress in the contact area. Contact stress is thereby estimated in relation with the contact area between materials, indirectly indicating average failure tangential stress in wood (shear stress $\tau_{s}$ ).

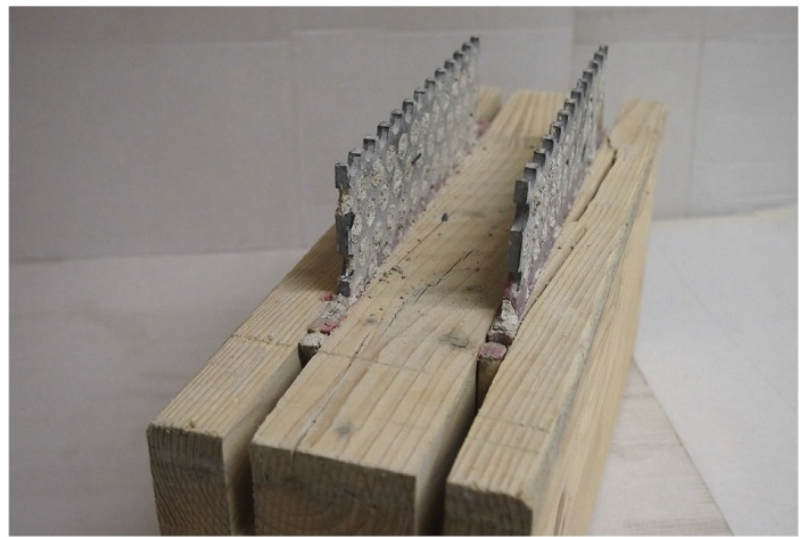

Fig. 3. Test result (failure mode)

The specimens with a shorter connector (T-180) showed a higher ultimate average stress than the longer connector specimens (T-300), indicating loss of adhesive joint effectiveness in relation to the increase in contact area length. The solutions without reinforcing bars (T1) reached an ultimate load slightly lower than the solutions with reinforcement (T2 and $\mathrm{T}_{3}$ ). There was a minimal difference between longitudinal and transverse reinforcement bars (8.5\% in T-180 and $12.7 \%$ in T-300). Detailed analysis of the test results, failure modes and system efficacy in terms of rigidity is provided by Otero-Chans et al. [37].

\section{Discussion}

\subsection{Load-Slip Descriptive Model}

It is possible to obtain an accurate description of the behaviour of a shear connector based on the linear elastic properties obtained in tests. Ollgaard et al. [38] describe the behaviour of stud connectors in concrete in a load-slip relationship depending on three empirical factors. Foschi [39] modified this exponential expression to describe the load-displacement behaviour of steel fasteners in timber. This proposal (1) shows three parameters associated with a yielding force (FP), hardening (KP) and initial joint stiffness (Ko).

$$
\begin{aligned}
F= & \left(F_{p}+K_{p} \cdot \delta\right) \cdot\left(1-e^{-\frac{K_{0} \cdot \delta}{F_{P}}}\right) \\
& F: \text { Load per shear plane per fastener } \\
& K_{0}: \text { Initial stiffness } \\
& K_{P}: \text { Post-yield stiffness } \\
& F_{P}: \text { Load at which the deformation changes from elastic to semi-plastic } \\
& \delta: \text { Slip or displacement }
\end{aligned}
$$

Jaspart and Maquoi [40] analyzed shear connection behaviour expressed in terms of force and slip, taking into account the Modified Richard-Abbot model for a joint in a 
bending moment-rotation relationship. In this case a new parameter " $\beta$ " is considered to improve the fit of the curve in the yielding zone (2).

$$
F=\frac{\left(K_{0}-K_{P}\right) \cdot \delta}{\left[1+\left(\frac{\left(K_{0}-K_{P}\right)}{F_{P}} \cdot \delta\right)^{\beta}\right]^{\frac{1}{\beta}}}+K_{P} \cdot \delta
$$

Dias et al [41] compared these mathematical models, finding adjustment parameters for a timber-concrete joint. The load-slip relationships obtained in tests are quasibilinear, so it is possible to obtain an accurate description based on linear elastic properties, considering Foschi's model in a $\mathrm{Kp} \approx 0$ o simplification (3).

$$
F=F_{\max } \cdot\left(1-e^{-\frac{K_{0} \cdot \delta}{F_{\max }}}\right) \rightarrow \delta=-\ln \left(1-\frac{F}{F_{\max }}\right) \cdot\left(\frac{F_{\max }}{K_{0}}\right)
$$

The aim of these expressions is to determine a suitable value for the slip modulus to be considered in a design process. In accordance with the EN 26891:1992 standard [36] it is possible to estimate the load-slip steps that determine the corresponding $K_{s e r}$. Based on Dias's proposal this consideration results in the next expression (4).

$$
K_{\text {ser }}=\frac{0,4 \cdot F_{\text {est }}}{\frac{4}{3} \cdot\left(\delta_{0,4}-\delta_{0,1}\right)}=\frac{0,4 \cdot F_{\text {est }}}{\frac{4 \cdot F_{\max }}{3 \cdot K_{0}} \cdot\left(\ln \left(1-\frac{0,1 \cdot F_{\text {est }}}{F_{\max }}\right)-\ln \left(1-\frac{0,4 \cdot F_{\text {est }}}{F_{\max }}\right)\right)}
$$

Nevertheless, in all of these expressions it is necessary to assume a previous value and refer to an initial stiffness $\left(K_{0}\right)$ that must be estimated in a test process. This model can be used as an operative expression to give a simplified description of the behaviour of a previously tested specific configuration, so that it cannot function as a previous design tool. On the other hand, no factors intervene in these expressions that depend on the particular properties of the constituent material or the geometric configuration of the connector.

A simplified expression is proposed to establish a predictive model in connection with a geometrical configuration. One of the aims of this research is to determine behaviour in association with the dimensions of the timber-adhesive contact zone. Table 02 shows the maximum test load obtained $\left(F_{\max }\right)$ and the average shear stress in timber in relation to the contact area $\left(\tau_{S}\right)$. Considering $F_{\max }$ (the maximum load resisted by the joint) the slip-force curve can be described by a novel expression (5) that comprises two complementary terms.

$$
\delta=\left[-\ln \left(1-\left(\frac{F_{i}}{F_{\max }}\right)^{\frac{\alpha}{10}}\right) \cdot\left(\frac{1}{2 \alpha}\right) \cdot\left(\frac{F_{i}}{F_{\max }}\right)^{\frac{1}{2 \alpha}}\right] \cdot \operatorname{Max}\left\{1: \ln \alpha^{\frac{F_{i}}{F_{\max }}}\right\}
$$

$\delta$ : Slip or displacement [mm]

$\mathrm{F}_{\mathrm{i}}$ : Load (in a certain step) [N]

$\mathrm{F}_{\max }$ : Maximum Load [N]

$\alpha=\frac{L_{A}}{h_{a}}$ : Dimensional factor, with:

$\mathrm{L}_{\mathrm{A}}$ : Length of the contact zone [mm]

$\mathrm{h}_{\mathrm{a}}$ : Deep of the contact zone [mm] 
The first term, in brackets, refers to the initial phase in which behaviour is linear, while the second term makes the adjustment corresponding to the plastic phase that precedes the collapse force. This expression makes it possible to reflect the slip-force curve for any load step in direct relation with the test results, determining an effective model to describe joint behaviour.

This simple expression fulfils a fundamental condition of the failure mode in relation to timber shear stress material capacity, having established this from the relationship between the ultimate failure load $\left(F_{\max }\right)$ and the contact area or adhesive interface zone. From this point it is possible to predict the behaviour of a joint by taking into account only two parameters: a mechanical timber property and the geometric configuration of the contact interface area.

Fig. 4 shows the slip-force curves obtained in testing a simple configuration (T1) and reinforcement configurations (T2) and (T3) with a minimum difference between (T2) and (T3). In addition to these results, the figures represent the curves obtained from Dias's simplified proposal and the new analytical model presented in this paper. The curves obtained by applying the new analytical model show a highly accurate fit with test results. The analytical model values fit the initial linear elastic phase exactly, and the curve corresponding to the subsequent plastic phase also fits with similar precision. A single expression without correction factors is able to describe behaviour in both the linear and plastic phases.

\subsection{The finite element method. Numerical model}

A direct approach with a 3D FEM model was developed using Ansys Workbench Academic Research V.18. The aim of numerical analysis is to evaluate the ability of the model to predict the mechanical behaviour obtained in laboratory tests. In this case the focus is to identify the most appropriate contact models to simulate the mechanical behaviour of the joint, so a variable force-frictional coefficient relation was implemented.

An orthotropic material was considered for timber with a longitudinal elastic modulus $E_{L} 11600 \mathrm{MPa}$ according to $\mathrm{EC} 5[1]$. The relations given by $E_{T} / E_{L}=0.043$, $E_{R} / E_{L}=0.078, G_{L R} / E_{L}=0.064, G_{L T} / E_{L}=0.061$ and $G_{R T} / E_{L}=0.003$, where $E_{T}$ and $E_{R}$ are the elastic moduli along the radial and the tangential axes and $G_{L R}, G_{L T}$ and $G_{R T}$ represent the corresponding shear modulus and Poisson ratio $\mu_{T R}=0.255, \mu_{T L}=0.058, \mu_{R L}=0.083$, $\mu_{R T}=0.382, \mu_{L R}=0.328$ and $\mu_{L T}=0.292$ are considered in accordance with conventional references [42].

A simplified bi-linear behavioural model was used for the stress-strain steel curve, with a constitutive law assumed to be isotropic as well as the material yield criterion. The hardening rule was assumed to be isotropic, the yielding strength $f_{y} 294 \mathrm{MPa}$ and the ultimate strength $f_{u} 392 \mathrm{MPa}$ were determined by laboratory test made by the suppliers, with a Young's modulus of $E_{s} 210000 \mathrm{MPa}$ and a Poisson ratio of $\mu_{s} 0.3$ [31].

Different analyses performed showed that concrete was subjected to small stresses and strains, therefore we have assumed that material was modelled as an isotropic elasto-plastic material with a yielding strength considered equal to its compression strength $\left(f_{c} 24.9 \mathrm{MPa}\right)$, elasticity modulus $\left(E_{c} 27264 \mathrm{MPa}\right)$ and Poisson ratio $\left(\mu_{\mathrm{c}} 0.2\right)$ established from the test results [ ]. 
F. Suárez-Riestra, J. Estévez-Cimadevila, E. Martín-Gutiérrez, D. Otero-Chans

sample 1

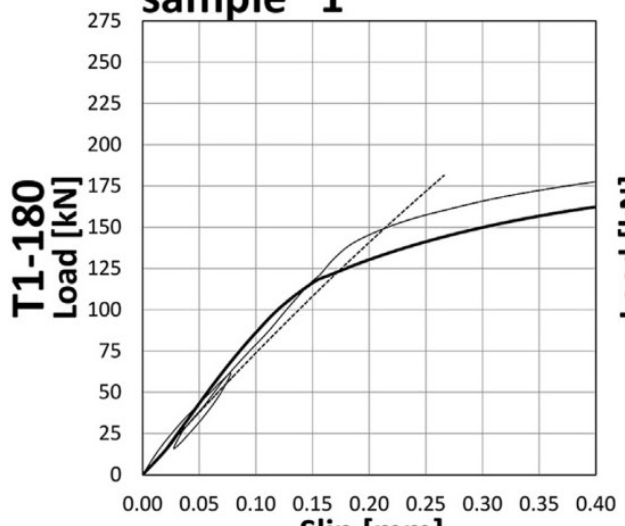

Slip [mm]

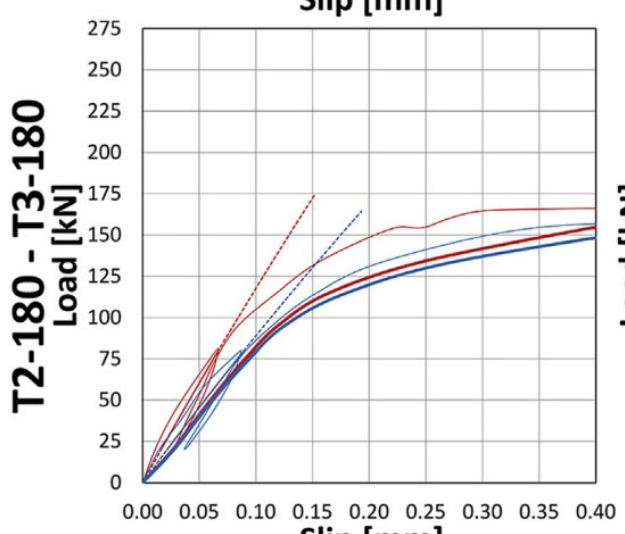

Slip [mm]
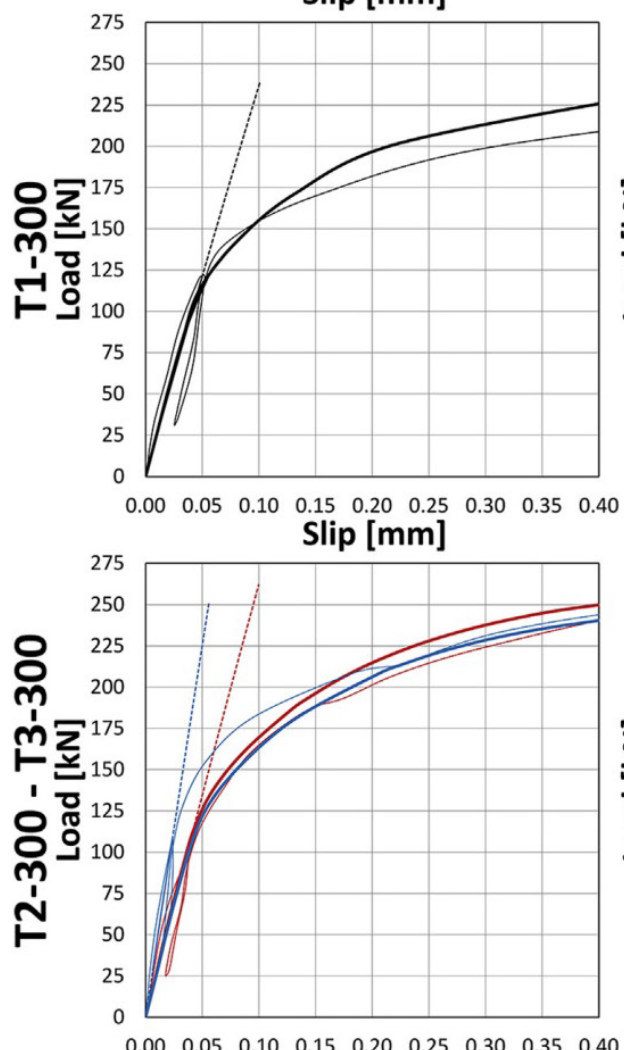

Slip [mm]
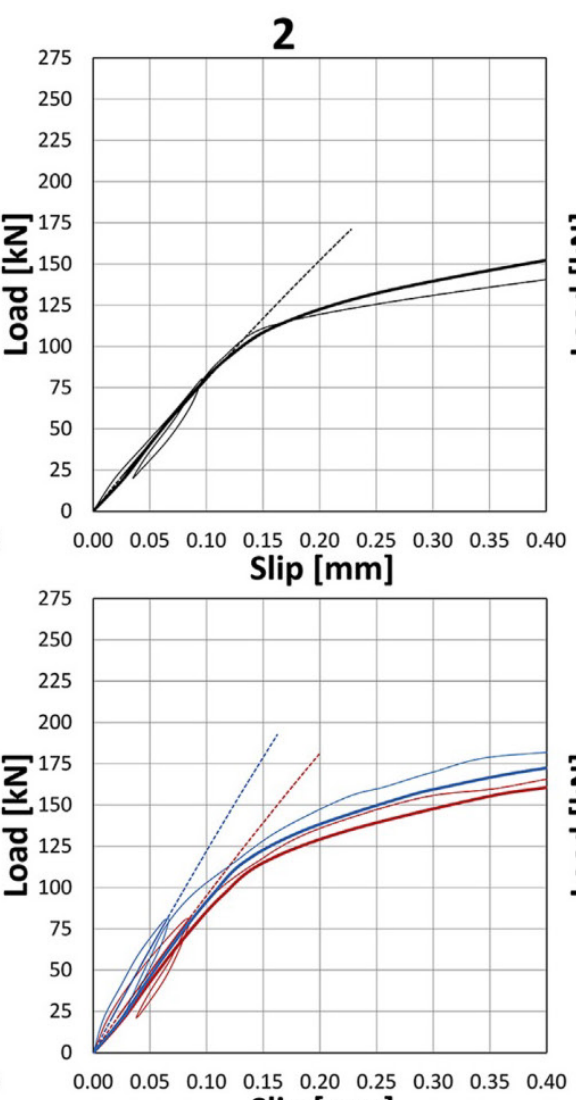

Slip [mm]

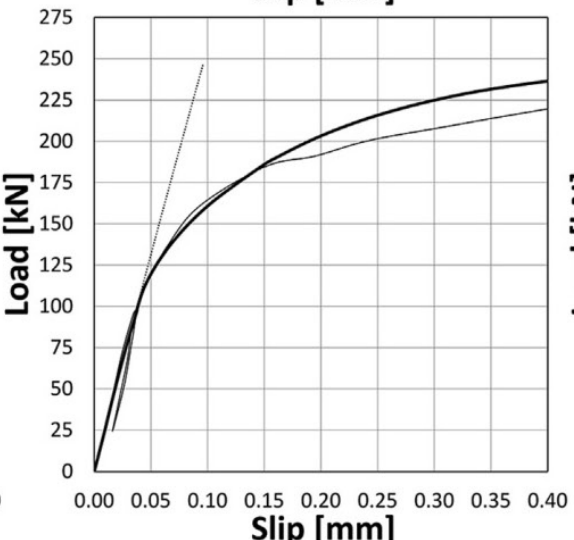

Slip [mm]

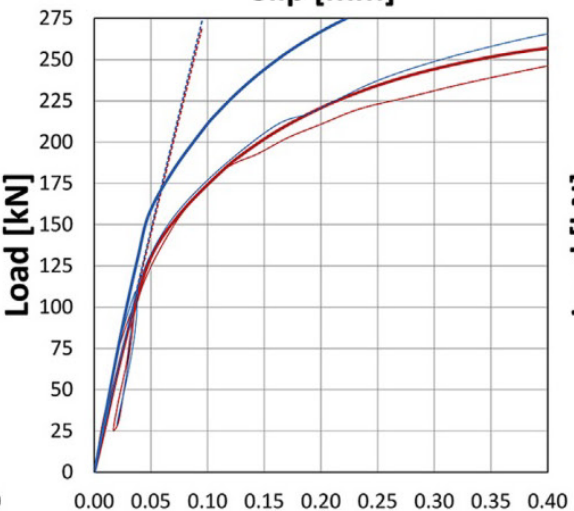

Slip [mm]

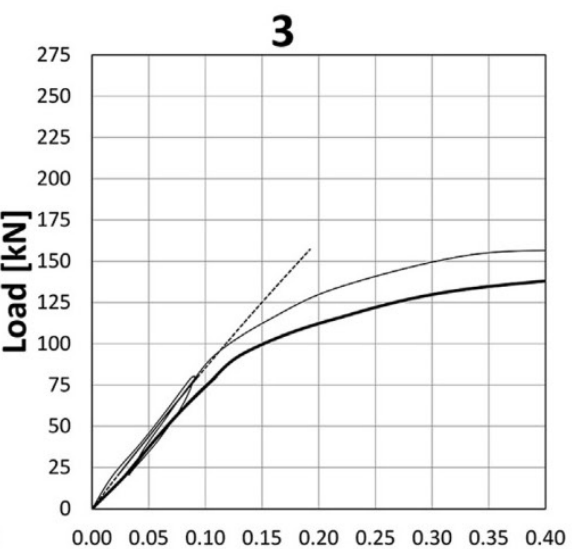

Slip [mm]

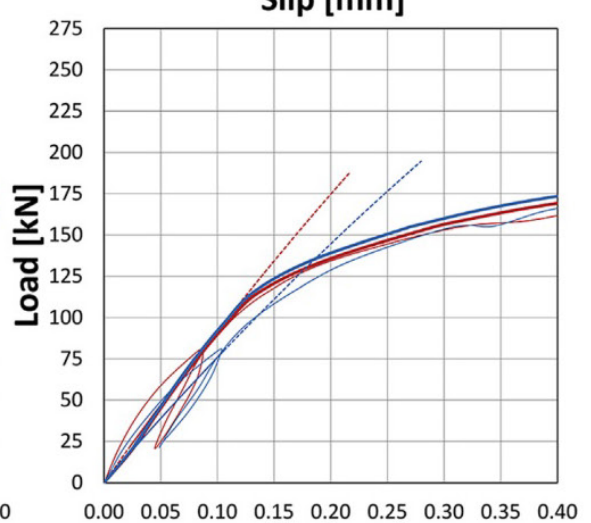

Slip [mm]
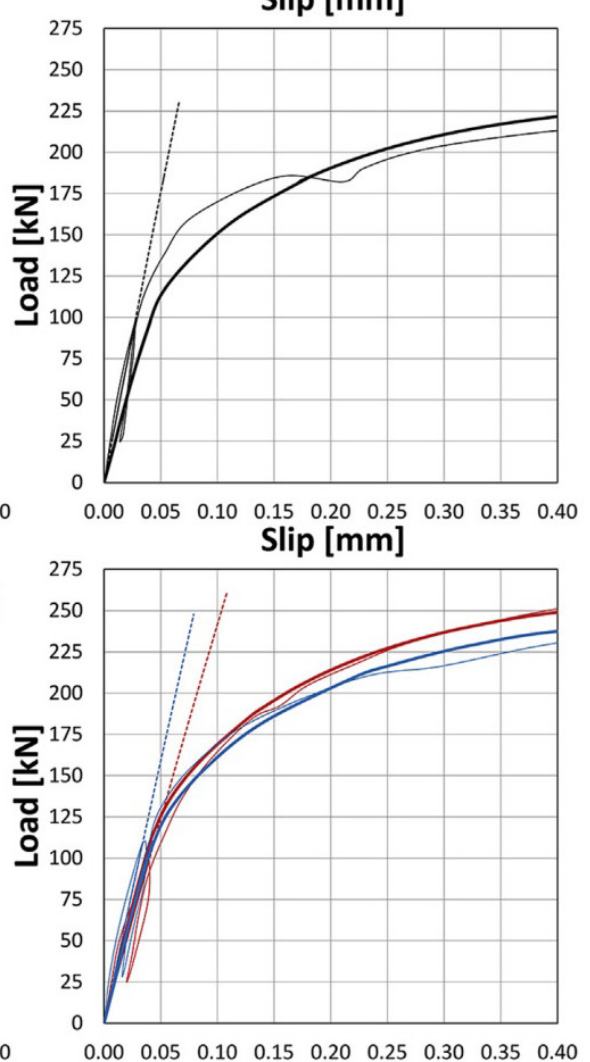

Slip [mm]

\begin{tabular}{|l|l|l|c|c|}
\hline \multicolumn{2}{|c|}{ Test Results } & Analytical Model & Días Simplified Model \\
\hline T1 & T2 & & $--\cdot-\cdot----\cdot$ \\
\hline
\end{tabular}

Fig. 4. Load-Slip Curves. Analytical and Dias Models in relation to test results. 
The material properties for modelling the adhesive joint were taken from the technical specifications of the product. Several previous models have been made, determining different stiffness criteria in the material, but without appreciable changes in the behaviour of the union, thus determining the minimum impact of the law constituting the material. So the adhesive was modelled as isotropic material with a Young's modulus of $E_{a} 7000 \mathrm{MPa}$ and a Poisson ratio of $\mu_{a}$ 0.3. During analysis it was assumed that the material is lineal elastic.

The elements considered have been Solid186 (3-D 20-Node Structural Solid) and Solid187 (3-D 10-Node Tetrahedral Structural Solid). The mesh process was carried out from refined process, with an adaptive size function, from an initial $5 \mathrm{~mm}$ element size in steel-adhesive-timber contact zone. Three iterations was carried out in a consecutive refinement of the elements in the contact zone. In the solution options an adaptive mesh refinement was employed, with a value of 1 (Max Refinement Loops) and 2 (Refinement Depth), with a default 20\% prescribed percent change in result. The final mesh was chosen for each case according to the best correspondence with the test results, with the slip as objective value (Fig. 5).

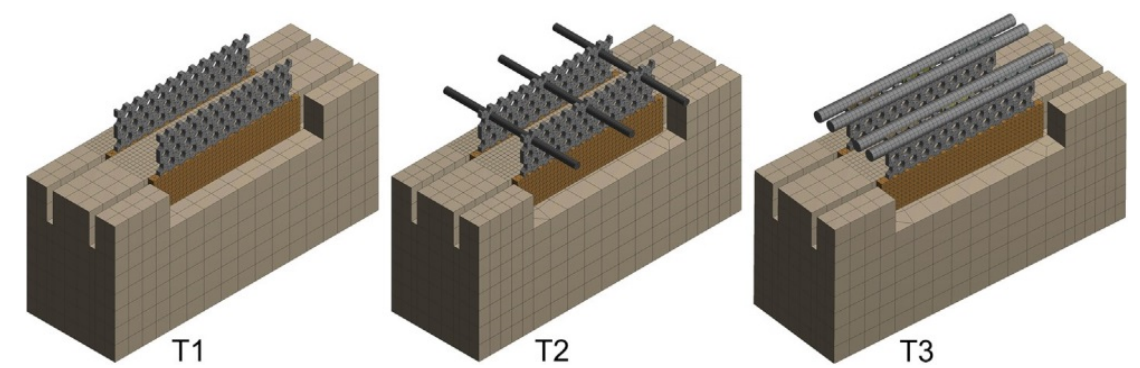

Fig. 5. Initial Mesh Geometry considered in FEM Models.

The interaction between the members was modelled using deformable contact elements. Under these conditions a multipoint constraint is imposed when a deformable body node contacts another deformable body, allowing the contacting node to slide over the contacted segment. A node can slide from one segment to another during the iteration procedure, changing the retained nodes associated with constraint. An isotropic friction stick-slip model is assumed for contact causing friction, and two different considerations were taken into account. Firstly, a model with a constant friction coefficient was assumed, according to the usual criterion in this type of analysis. Secondly, a model with a variable friction coefficient (MU) was implemented using the APDL Ansys TBFIELD command in relation to a sliding distance (SLDI) and time (TIME) dependency. In both cases a time-dependent model was developed in accordance with the standard test, in 30 second steps, and the corresponding applied force was considered in any step. A expression was developed to determine the friction coefficient in any time step, taking into account the ultimate failure load $\left(F_{\max }\right)$. Considering a time step $(i)$ from $1, \ldots, i, \ldots, n$ the corresponding friction coefficient $\left(M U_{i}\right)$ can be expressed by the next expression (6) and graphically represented in Fig. 6.

$$
\begin{aligned}
& M U_{i}=\left(\frac{F_{\max }}{10}\right) \cdot\left(\frac{n-i}{n}\right)^{2} \\
& \mathrm{MU}_{\mathrm{i}} \text { : Friction coefficient }[\mathrm{mm}] \\
& \mathrm{F}_{\max } \text { : Maximum Load }[\mathrm{kN}] \\
& \quad \mathrm{i} \text { Time or step } \\
& \mathrm{n} \text { : Total time or steps considered }
\end{aligned}
$$




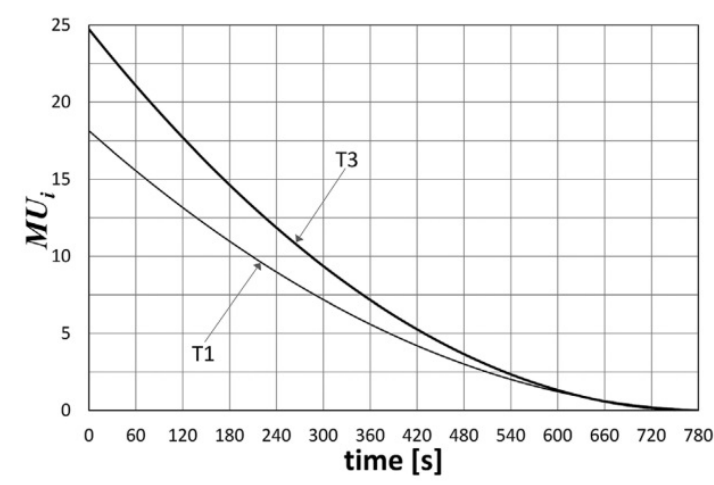

Fig. 6. MUivariable friction coefficient.
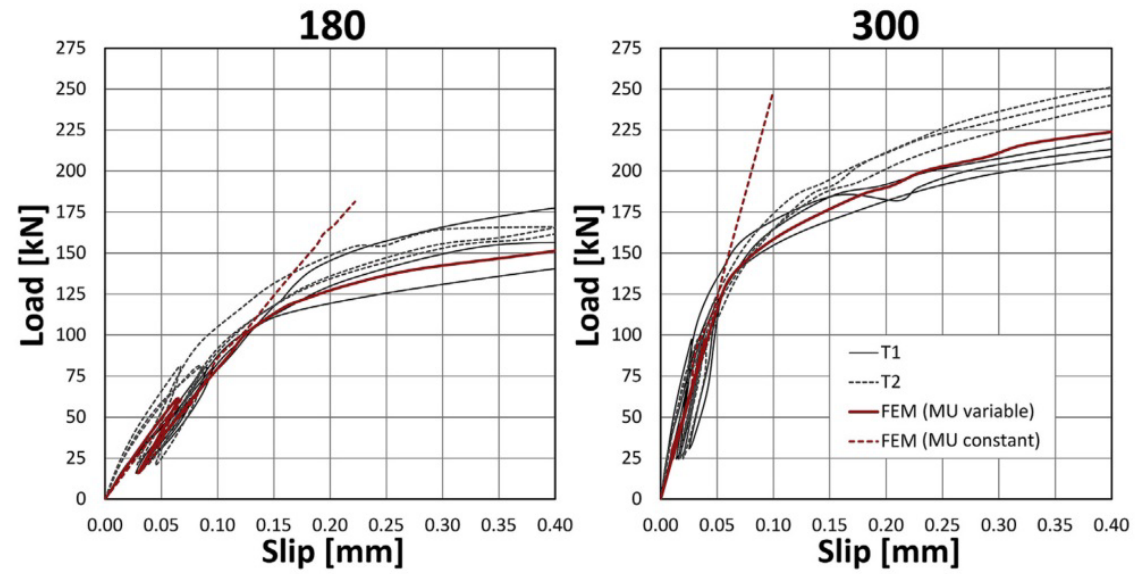

Fig. 7. FEM model. Load-slip comparison (T-180 and T-30o).

Fig. 7 show the load-slip curves obtained in FEM models in comparison with the test results for T1-180 and T2-180 and T1-300 and T2-300 specimens. The proposed model with a variable friction coefficient shows behaviour more precisely than the most common FEM model in which contact is considered to be a constant factor.

Compared to other models that only include nonlinear analysis with a constant coefficient, the variable coefficient of friction makes it possible to reproduce behaviour with extreme precision even in loading and unloading steps, and most especially in the plastic phase. The accuracy of the model in accordance with the time-load steps considered in test procedures would permit detailed analysis of behaviour, not only in terms of load-slip, but also in terms of stress and strain distribution according to the materials and contact area

\section{The analytical model as a design tool.}

The analytical expression (5) makes it possible to describe joint behaviour in terms of stiffness in relation to geometric configuration and maximum load. The factors on which this behaviour depends result from the direct relationship between the contact area and the tangential stress capacity of the timber, that is, its mechanical properties. Given this consideration the proposed model is also predictive, and it is able to define joint behaviour with a precision directly related to the precision with which the mechanical timber properties are determined, particularly the shear strength value. These two considerations give the expression predictive capacity as a design tool. The relationship between joint capacities, evaluated in terms of maximum load and the consequent 
average shear stress in the contact interface makes it possible to establish new design criteria. For a certain shear strength value, i.e. the characteristic value, it is possible to estimate a maximum contact load $\left(F_{\text {predict }}\right)$ in relation to the systematic failure mode shown by tests. Therefore this contact maximum load is equivalent to the maximum load $\left(F_{\max }\right)$ determined in testing, and due to this the analytical model can be applied.

By applying the proposed expression to the loading steps that determine the value of the slip modulus $\left(K_{S}\right)$ in accordance with the standard [36] proposal, a new simplified expression can be developed (9) that determines an analytical slip modulus $\left(K_{a}\right)$. The accuracy of the result obtained in comparison with the slip moduli obtained in tests will be in direct relation with the precision of the timber shear strength value considered.

$$
\begin{aligned}
& \delta_{0,1}=-\ln \left(1-(0.1) \frac{\alpha}{10}\right) \cdot\left(\frac{1}{2 \alpha}\right) \cdot(0.1)^{\frac{1}{2 \alpha}} \\
& \delta_{0,4}=-\ln \left(1-(0.4)^{\frac{\alpha}{10}}\right) \cdot\left(\frac{1}{2 \alpha}\right) \cdot(0.4)^{\frac{1}{2 \alpha}} \\
& K_{a}=\frac{0.4 \cdot F_{\max }}{\frac{4}{3}\left(\delta_{0,4}-\delta_{0,1}\right)}=\frac{0.6 \cdot F_{\max } \cdot \alpha}{\ln \left(1-(0.1)^{\frac{\alpha}{10}}\right) \cdot(0.1)^{\frac{1}{2 \alpha}}-\ln \left(1-(0.4)^{\frac{\alpha}{10}}\right) \cdot(0.4)^{\frac{1}{2 \alpha}}}
\end{aligned}
$$

Table 3 shows the results of the slip module $\left(K_{s}\right)$ according to the test process and the corresponding slip modulus from the analytical model $\left(K_{a}\right)$. The greater difference between compared values is direct related with what has been said regarding the distortion of results that causes the difference between a previous Fest and the $F_{\max }$ obtained in testing. Thus the greatest deviation between Fest and Fmax results in the biggest difference between the slip modulus obtained in testing $\left(K_{s}\right)$ and the analytical slip modulus $\left(K_{a}\right)$ obtained from the analytical model.

Table 3: Slip moduli: comparative results from testing, the analytical model and the predictive proposal.

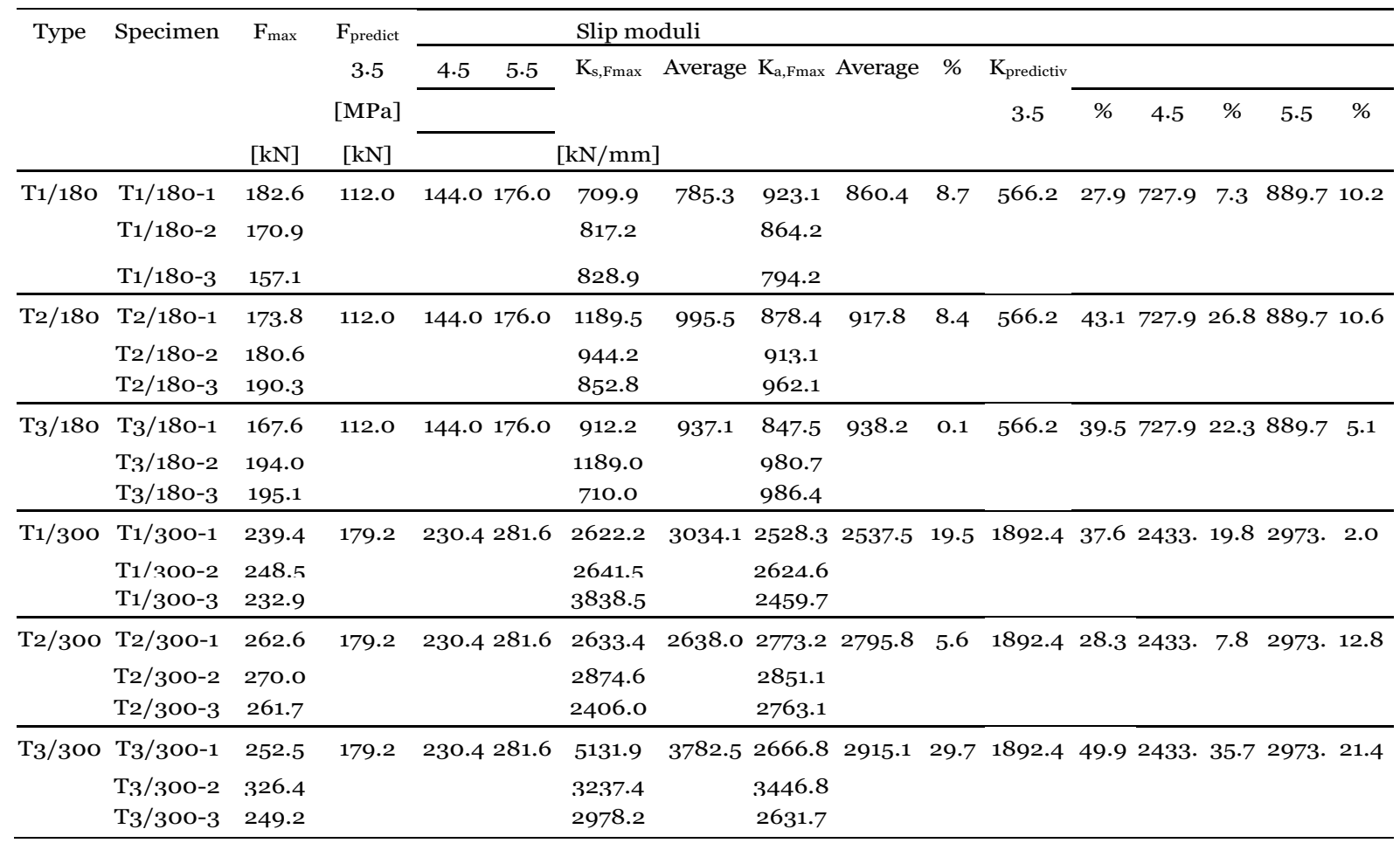


The accuracy of these results makes it possible to consider this as a design tool to determine joint stiffness. The analytical slip modulus corresponds to a real stiffness factor that in turn corresponds to the ultimate capacity of the joint, and this capacity is related to the mechanical properties of the timber and the geometric proportions of the contact area. So for a specific geometric configuration of the proposed contact area it is possible to establish behaviour in slip-load terms from the value of the timber shear strength considered.

The determination of $K_{s}$ value is a fundamental factor in a composite section analysis that usually requires the performance of characterization tests for each possible configurations. Recent studies have shown the dependency between shear strength and shear-stressed zones [43,44], especially for adhesive solutions [45]. In addition, previous tests on solutions with adhesives and timber sections have shown that timber presents shear strength value higher than one established by standard [34] as a characteristic value $\left(f_{v, k}\right)$. From a certain value of shear strength an $F_{\text {predict }}$ force can be determined for a geometric configuration of the contact zone, so the load-slip behaviour can be determined by applying the proposed analytical model. Fig. 8 show the comparative load-slip results for different values of $f_{v}$, from 3.5 to $5.5 \mathrm{MPa}$ in relation to testing load-slip curves for the T1-180 and T1-300 configurations. The higher accuracy of $f_{v} 5.5 \mathrm{MPa}$ in T180 configurations and $\mathrm{fv} 4.5 \mathrm{MPa}$ in T300 configurations, respectively, is an indicator of the effectiveness of adhesive joints in relation to the length of the contact area [46].
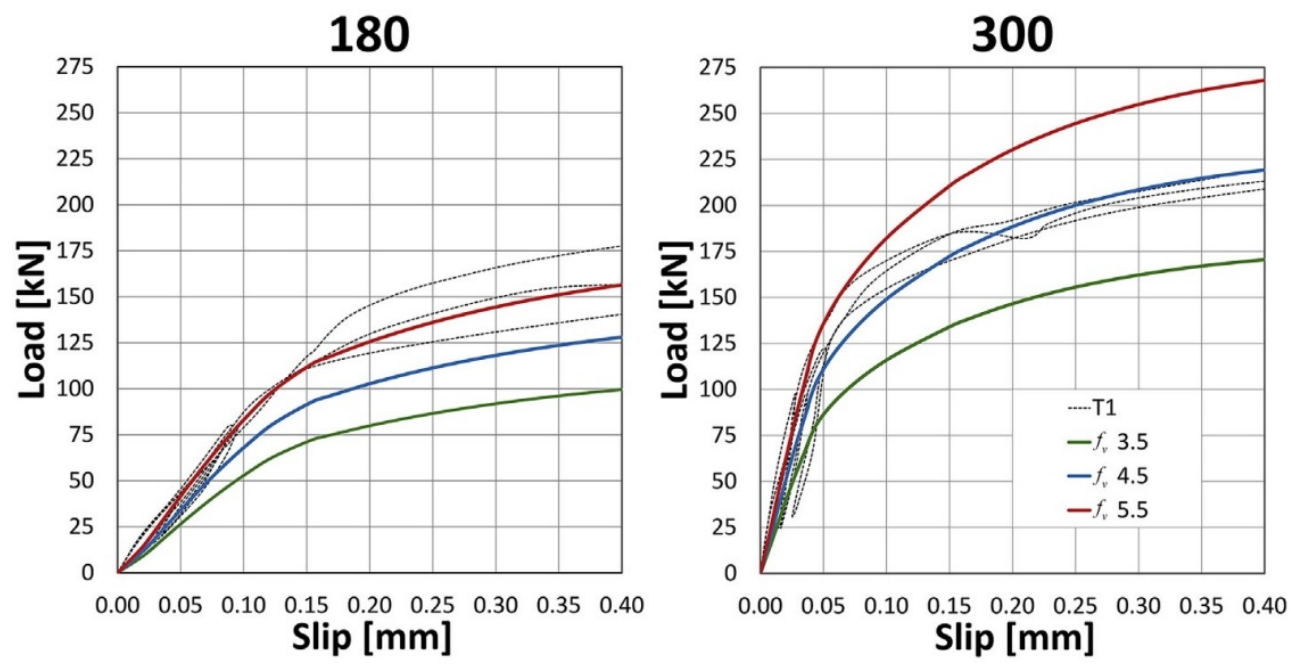

Fig. 8. Load-slip curves ( $\mathrm{f}_{\mathrm{v}}$ comparison) (T1-18o and T1-30o).

Taking into account this Fpredict value, a slip modulus $\left(K_{\text {predict }}\right)$ can be estimated from the proposed expression (9). Comparative results between this predictive modulus and the slip modulus obtained in testing are shown in Table 3. These determinations make it possible to estimate a slip modulus that can be considered sufficiently safe in the absence of joint behaviour characterization tests.

\section{Conclusion}

There are previous analytical expressions to describe the slip-load behaviour of a composite system, not being able to establish any relationship between the material and geometric configuration of the joint and the result obtained. Furthermore, in 
order to adequately describe the behaviour in the linear phase and in the plastic phase, they require the inclusion of correction factors, resulting in extremely complex expressions. The new proposal presents a simple expression that allows defining the behaviour in both phases, without needing to establish more correction factors and does so taking into account only two factors. On the one hand the geometry of the plate-timber contact zone $(\alpha)$ and on the other an ultimate load value $\left(F_{\max }\right)$ supported by the joint. The determination of the failure mode has allowed to relate the ultimate load with the shear stress $\left(\tau_{s}\right)$ in the contact zone and with the timber shear strength $\left(f_{v}\right)$. It is therefore possible to establish a predictive load equivalent $\left(F_{\text {predict }}\right)$ for each geometric configuration from a given value of shear strength. Using this value in the proposed expression it is possible to predict the behaviour of the joint in load-slip terms. Therefore, this expression allows to establish a simple design rule for the determination of the slip module $K_{s}$. The proposed analytical model is therefore a design tool.

The complexity of the FEM numerical model is directly related to the accuracy of its results. For stress-strain behaviour analyses it is extremely important to have a model that accurately reflects the influence of each geometric factor and each mechanical property of the constituent materials. The use of the variable friction coefficient $\left(M U_{i}\right)$ exceeds the global descriptive target of the most common nonlinear analyses. Defining a coefficient of friction that is dependent on time, load or sliding distance allows a greater precision in the reproduction of results, being able to analyse in greater detail the stress-strain behaviour in any component.

Both methodologies, analytical and numerical, generate greater precision in the study of shear connector behaviour in timber-concrete composite solutions compared to previous proposals. This is achieved without increasing the complexity of the analytical process, establishing new and more precise factors on which the behaviour of the system depends.

Future research will evaluate the descriptive and predictive capacity of the proposed model in relation to new joint configurations whose design has evolved from the above results and conclusions.

\section{Acknowledgments}

This research is part of the research project "Self-tensioning structural high performance floors with glued laminated timber-fibre reinforced concrete composite section" (BIA2016-77184-P) financed by the Spanish Ministry of Economy and Finance and the European Regional Development Fund (ERDF).

\section{References}

[1] UNE EN 1995-1-1. Eurocode 5: design of timber structures- Part 1-1: general- Common rules and rules for Building. Brussels: European Committee for Standardization; 2004.

[2] Möhler K. On the load carrying behaviour of beams and columns of compound sections with flexible connections Habilitation Technical University of Karlsruhe; 1956.

[3] Schänzlin J, Fragiacomo M. Extension of EC5 Annex B formulas for the design of timber concrete composite structures Meeting forty of the Working Commission W- 18-Timber Structures Rotterdam: CIB, International Council for Research and Innovation in Building and Construction; 2007.

[4] Ceccotti A, Fragiacomo M, Gutkowski R. Design of timber-concrete composite structures according to $\mathrm{EC}_{5-2002}$ version. Proceedings of the meeting thirty-five of the working 
commission W18-Timber structures. Kyoto: CIB, International Council for Research and Innovation in Building and Innovation; 2002.

[5] Van der Linden MLR. Timber Concrete composite floor system PhD. Thesis Delft University of Technology; 1999.

[6] Frangi A, Fontana M. Elasto-plastic model for timber-concrete composite beams with ductile connection. Struct Eng Int 2003;13(1):47-57.

[7] Zhang C, Grauvreau P. Timber-concrete composite systems with ductile connec- tions. J. Struct. Eng. 2015(7):141.

[8] Fragiacomo M. A finite element model for long-term analysis of timber-concrete composite beams. Struct Eng Mech 2005;22(2):173-89.

[9] Liu C. Modelling of timber-concrete composite structures subjected to short-term monotonic loading PhD. Thesis University of Toronto; 2016.

[10] Van de Kuilen JW, Dejong M. 3D-Numerical modelling of DVW reinforced joints. Proceedings of 8th world conference on timber engineering WCTE. 2004. [Helsinki, Finland].

[11] Dias AMPG, Van de Kuilen JW, Lopes S, Cruz H. A non-linear 3D FEM model to simulate timber-concrete joints. Adv Eng Software 2007;38:522-30.

[12] Penado FE, Dropek RK. Numerical design and analysis of bonded joints. ASM in- ternational engineered materials handbook, vol. 3. "Adhesives \& Sealants", ASM International; 1990. p. 447-500.

[13] Tessler A, Dambach ML, Oplinger DW. Efficient adaptive mesh refinement modelling of adhesive joints. Workshop on bonded joints and assemblies in aircraft. Texas AM: ASTM/ASC; September 2000.

[14] Xiacong H. A review of finite element analysis of adhesively bonded joints. Int J Adhesion Adhes 2011;31:248-64.

[15] Gereke T, Hering S, Niemz P. Finite element analysis of wood adhesive joints. Forestry and Wood Technology 2015;89:36-49.

[16] Vavrusova K, Lokaj A, Mikolasek D, Fojtik R, Zidek L. Longitudinal glued joint of timber beams and the influence of quality manufacturing onto their carrying ca- pacity. Wood Res 2016;61(4):573-82.

[17] Lavalette NP, Bergsman OK, Zarouchas D, Benedictus R. Comparative study of adhesive joint designs for composite trusses based on numerical models. Applied Adhesive Science 2017;5:20.

[18] Calí C, Cricrí G, Perrella M. An advanced creep model allowing for hardening and damage effects. Strain 2010;46:347-57.

[19] Berardi VP, Feo L, Mancusi G, De Piano M. Influence of reinforcement viscous properties on reliability of existing structures strengthened with externally bonded composites. Compos Struct 218; 200, 535-539.

[20] Ceccotti A. Composite concrete-timber structures. Prog Struct Eng Mater 2002;4(3):264-75.

[21] Dias AMPG. Mechanical behaviour of timber-concrete joints PhD Thesis TUDelft University; 2005

[22] Lukaszewska L, Johnsson H, Fragiacomo M. Performance of connections for pre- fabricated timber-concrete composite floors. Mater Struct 2008;41:1533-50.

[23] Pincus G. Behaviour of wood-concrete composite beams. J Struct Div 1970;69(10). 2009-2019.

[24] Brunner M, Romer M, Schnüriger M. Timber-concrete-composite with an adhesive connector (wet on wet process). Mater Struct 2007;40:119-26.

[25] Kanócz J, Bajzecerová V. Timber-concrete composite elements with various com- posite connections. Part 3: adhesive connection. Wood Res 2015;60(6):939-52.

[26] Ceccotti A, Fragiacomo M, Giordano S. Long-term and collapse tests on a timber- concrete composite beam with glued-in connection. Mater Struct 2006;40(1):15-25.

[27] Piazza M, Ballerini M. Experimental and numerical results on timber-concrete composite floors with different connection systems. Proceedings of 6th world conference on timber engineering WCTE. 2000. [British Columbia, Canada]. 
[28] Bathon LA, Graf M. A continuous wood-concrete-composite system. Proceedings of 6th world conference on timber engineering WCTE. 2000. [Whistler, Canada].

[29] Clouston P, Bathon L, Schreyer A. Shear and bending performance of a novel wood-concrete composite system. ASCE Journal of Structural Engineering 2005;131(9):1404-12.

[30] Daňková J, Mec O, Majstríková T. Stiffness analysis of glued connection of the timber concrete structure. Open Eng 2016;6:241-9.

[31] UNE EN 10025-2. Hot rolled products of structural steels-Part 2: technical delivery conditions for non-alloy structural steels. Brussels: European Committee for Standardization; 2006.

[32] DIN 24041. 12: perforated plates. Dimensions. Berlin: Din Standards Committee Building and Civil Engineering; 2002.

[33] UNE EN 36068. Ribbed bars of weldable steel for the reinforcement of concrete. Brussels: European Committee for Standardization; 2011.

[34] UNE EN 14080. Timber structures. Glued laminated timber and glued solid timber Requirements Brussels: European Committee for Standardization; 2013.

[35] UNE EN 14889-2. Fibres for concrete - Part 2: polymer fibres. Definitions, specifications and conformity. Brussels: European Committee for Standardization; 2008. [36] UNE EN 26891. Timber structures. Joints made with mechanical fasteners. General Principles for the determination of strength and deformation characteristics (ISO 6891:1983). Brussels: European Committee for Standardization; 1992.

[36] UNE EN 26891. Timber structures. Joints made with mechanical fasteners. General Principles for the determination of strength and deformation characteristics (ISO 6891:1983). Brussels: European Committee for Standardization; 1992.

[37] Otero D, Estévez J, Suárez F, Martín E. Experimental analysis of glued-in steel plates used as shear connectors in timber-concrete-composites. Eng Struct 2018;170:1-10.

[38] Ollgaard JG, Slutter RG, Fisher JW. Shear strength of stud connectors in lightweight and normal-weight concrete. Engineering Journal. AISC 1971;8(2):55-64.

[39] Foschi RO. Load-slip characteristics of nails. Wood Sci 1974;7(1):69-76.

[40] Jaspart JP, Maquo R. Prediction of the semi-rigid and partial-strength properties of structural joints. Proceedings of the annual technical session and meeting, SSRC. Lehigh; 1994. p. 177-92.

[41] Dias AMPG, Martins ARD, Simões LMC. Statistical analysis of timber-concrete connections. Mechanical properties. Comput Struct 2015;155:67-84.

[42] Handbook Wood. Wood as an engineering material General Technical Report FPL-GTR-113 USDA; 1999

[43] Crocetti R, Gustafsson PJ, Danielsson H, Emilsson A, Ormarsson S. Experimental and numerical investigation on the shear strength of glulam W18-Timber Structures, CIB-W18 Proceedings of international council for research and innova- tion in building and constructionNelson, New Zealand: Working Commission; 2010.

[44] Brandner R, Gatterning W, Schickhofer D. Determination of shear strength of structural and glued laminated timber W18-Timber Structures, CIB-W18 Proceedings of International Council for Research and Innovation in Building and ConstructionVäxjö, Sweden: Working Commission; 2012. 45-12-2.

[45] Otero-Chans D, Estévez-Cimadevila J, Martín-Gutiérrez E. Withdrawal strength of threaded steel rods glued with epoxy in wood. Int J Adhesion Adhes 2013;44:115-21.

[46] Otero-Chans D, Estévez-Cimadevila J, Martín-Gutiérrez E. Orientation of bars glued on glued laminated products: parallel vs. perpendicular. Composites Part B 2014;62:97-103. 